\title{
Determinants of Early Alcohol and Drug Use Among Young Women in Alcoholism Treatment
}

\author{
Maureen A. Walton \\ Edith S.L. Gomberg \\ University of Michigan Alcohol Research Center
}

\begin{abstract}
Substance abuse experimentation may be one of several types of problem behaviors. Data from 99 Caucasian women interviewed in alcoholism treatment (19-29 years old) were used to test a developmental model of substance experimentation. Respondents were classified into three groups based on their use prior to age 15: nonusers, users of alcohol only, and users of alcohol and other drugs. Family history of alcoholism was not related to childhood anxiety and impulse control problems. Childhood anxiety and impulse control problems predicted adolescent emotional and impulse control problems but did not differentiate early experimenters. Whereas adolescent emotional problems were not related to early experimentation, early drug and alcohol users were significantly more likely to have engaged in other impulsive behaviors (e.g., running away from home, trouble with school authorities) than were nonusers or users of alcohol only. Alcoholism prevention programs, therefore, would do well to target youth who exhibit acting-out behaviors as a highrisk group for early alcohol and drug use.
\end{abstract}

Experimentation with drugs and alcohol is related to other types of acting-out behaviors, with school transitions being particularly risky periods (Breslau, Fenn, \& Peterson, 1993; Donovan \& Jessor, 1985; Jessor \& Jessor, 1977; Osgood, Johnston, O'Malley, \& Bachman, 1988; Robins \& Przybeck, 1985). From a social learning perspective, peer influences are used to explain initial experimentation and continued use through association with peer groups that approve of deviance and alienation from peer groups that disapprove of substance use (Jessor \&c Jessor, 1977; Kandel, 1978). Although peer influences are important (Kumpfer \& Turner, 1991; Schulenberg, Dielman, \& Butchart, 1994), experimentation also may be determined by a complex developmental sequence. For example, experimentation may be biopsychologically based, because having a history of childhood behavior problems, particularly impulsivity, is related to alcohol and drug problems (Gomberg, 1989; Robins \& Przybeck, 1985; Scaturo \& LeSure,

This research was supported by NIAAA Grant AA07477. Comments by Lisa Thomson Ross on an earlier version of this article are greatly appreciated.

Correspondence and requests for reprints should be sent to Maureen A. Walton, University of Michigan Alcohol Research Center, 400 E. Eisenhower Parkway, Building 2, Suite A, Ann Arbor, MI 48108-3318. 
1985; Zucker, 1978). Knowledge of developmental paths leading to alcohol and drug experimentation and related risk behaviors is useful for providing targets for prevention efforts (Kandel, 1989). Thus, the purpose of this study was to test a developmental model of substance use experimentation based on family histories, and childhood and adolescent emotional and impulse control problems in a sample of young women in alcoholism treatment.

When conceptualizing a developmental model of substance experimentation, it is important to consider biopsychosocial indicators from childhood. $R e$ searchers have noted the relationship between family history of alcoholism and childhood emotional and impulse control problems. Fathers' problem drinking was a key causal agent of boys' behavior problems from infancy to childhood, and children with alcoholic parents were more impulsive than children whose parents were not alcoholics (Fitzgerald et al., 1993). Another study found that having an alcoholic mother predicted children's emotionality, which predicted substance use (Chassin, Pillow, Curran, Molina, \& Barrera, 1993). Longitudinally, children of alcoholics who later developed alcohol problems had significantly less self-control than those who did not develop problems (Werner, 1986). Alternatively, the disruption caused by alcoholism in the family may be a better predictor of childhood behavior problems, although this relationship has not been as extensively studied. One study found that families with positive family histories of alcoholism were more likely to have family disruption and that family disruption was related to children's impulse control, emotional problems, and later alcoholism (Bennett, Wolin, \& Reiss, 1988). Among male and female college students, positive family history was related to impulsivity in one study (Sher, Walitzer, Wood, \& Brent, 1991) but not another (Berkowitz \& Perkins, 1988). This inconsistency may be related to differing ability of each study to detect small effects (Chassin et al., 1993) or to the failure to consider the degree of family disruption caused by having an alcoholic parent.

Substance use experimentation is often conceptualized as one of several types of impulsive or deviant behaviors that are undesirable to adult society and typically result in a social control response (Jessor \& Jessor, 1977). Research shows that for adolescent boys and girls, unconventional or antisocial behaviors such as trouble in school, substance use, sexual activity, and general deviancy (e.g., truancy, fighting) are related (Donovan \& Jessor, 1985; Kandel, 1989; Kumpfer \& Turner, 1991; Osgood et al., 1988) and that involvement in other problem behaviors increases with increasing involvement with alcohol and other drugs (Donovan \& Jessor, 1983).

Many researchers have noted the relationship between impulsivity (Gomberg, 1989; Gomberg \& Lisansky, 1984; Honzik, 1984; Jones, 1971; Zucker, 1978) and anxiety (Scaturo \& LeSure, 1985) and alcohol problems for both women and men. History of childhood behavior problems or antisocial behavior also predicted alcohol problems (Drake \& Vaillant, 1988; Gomberg, 1989; Harford \& Parker, 1994; Scaturo \& LeSure, 1985; Zucker, 1978) and predicted drug problems (Robins \& Przybeck, 1985). When comparing alcoholic women to nonalcoholic women, however, Gomberg (1989) found that, although the two groups differed on childhood impulsivity (e.g., temper tantrums) and emotional distress, they did not differ on adolescent impulsive behaviors related to difficulty with authority. 
Few studies have examined the relationship between childhood anxiety and impulse control problems, adolescent emotional and impulse control problems, and early experimentation with substances. Robins and Przybeck (1985) found that antisocial personality and impulse control behaviors were related to early use of drugs. Another study found that children's emotionality indirectly predicted substance use (Chassin et al., 1993).

Research identifies critical periods in which substances are more likely to be experimented with and when this experimentation is most problematic. Earlier use of alcohol and/or cigarettes (age 14 as compared to 16) predicted greater involvement with other illicit drugs (Kandel, Yamaguchi, \& Chen, 1992; Yamaguchi \& Kandel, 1984b). Among both boys and girls, Robins and Przybeck (1985) found that drug use before age 15 was associated with increased risk for later psychological diagnoses such as antisocial personality, depression, dysthymia, and phobia disorders. Use before age 15 also was characterized by a greater number of predictors including discipline, alcohol drunkenness, stealing, vandalism, truancy, and panic attacks. Among African American boys, earlier use of marijuana is associated with greater risk of using other illicit drugs and greater risk for addiction or regular use (Robins \& Murphy, 1967). Thus, critical periods for substance use may occur during adolescent transitions such as upon entering high school.

Substance abuse prevention programs sometimes focus on delaying experimentation with alcohol. The rationale for this approach is that extensive research has documented "gateway" theories of substance abuse which state that alcohol and cigarettes are used before illicit drugs (Kandel, 1989; Yamaguchi \& Kandel, 1984a). It follows, therefore, that prevention of use of alcohol would reduce involvement with other drugs. The effects of early use remain to be determined. For both men and women, those who began smoking cigarettes between 14 and 16 years old were more likely to develop dependence later in life than those who began smoking at younger or older ages (Breslau et al., 1993). Delay of regular, daily cigarette smoking among men and women has been related to decreased number of cigarettes smoked in later life (Breslau, 1993). Thus, early experimenters may become more involved in using other substances.

This study examined childhood and adolescent emotional and impulse control problems and the use of alcohol and drugs during early adolescence (13-15 years old) among young women in alcoholism treatment. Early adolescence is developmentally interesting because it coincides with making the transition from junior high to high school, and research has shown that this is a critical period for experimentation with substances (Kandel et al., 1992; Robins \& Murphy, 1967; Robins \& Przybeck, 1985; Yamaguchi \& Kandel, 1984b). The sample used for testing this relationship (women in their 20 s who are in treatment for alcoholism) was chosen for several reasons. Alcoholic women are more likely than nonalcoholic women to show childhood and adolescent emotional and impulse control problems (Gomberg, 1989). Among alcoholics, younger women are more likely to show impulse control problems than older women (Gomberg, 1989). This population would be likely to have positive family histories for alcoholism, exhibit anxiety and impulse control problems, and use substances. Although few researchers have examined the determinants of substance experimentation spe- 


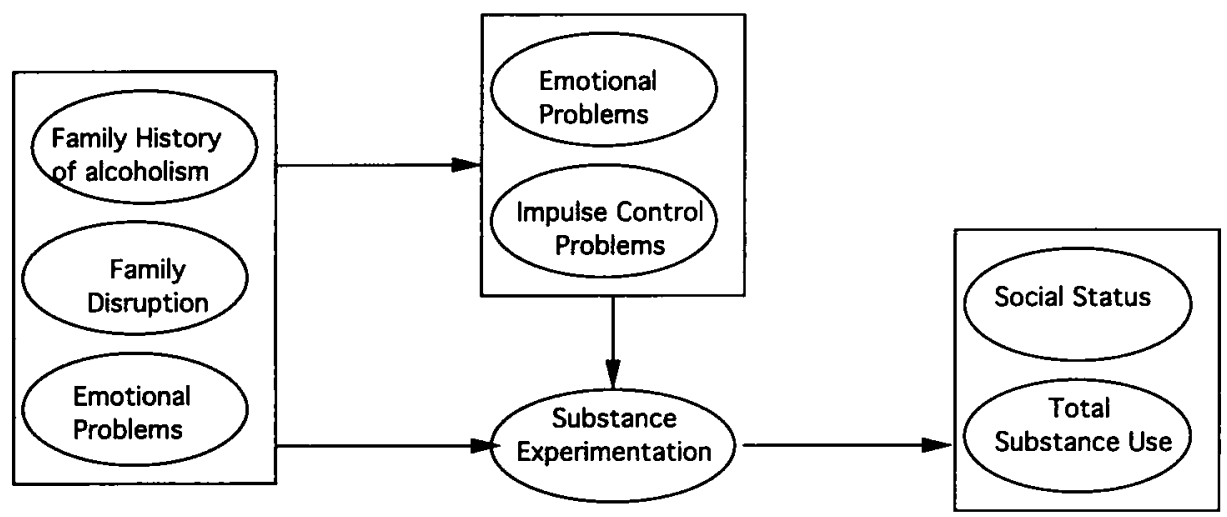

Figure 1. Theoretical model.

cifically for women, early prescribed social roles and eventual social and psychological factors associated with alcoholism clearly differ by gender (Gomberg, 1991), and the relationship between specific delinquent behaviors and substances varies by gender (Yamaguchi \& Kandel, 1984b).

Figure 1 illustrates the theoretical model that guided this research. This research tests the following hypotheses:

1. Childhood family disruption and family history of alcoholism will be related to childhood anxiety and impulse control problems.

2. Childhood anxiety and impulse control problems will be related to adolescent emotional problems, impulse control problems, and experimentation.

3. Adolescent emotional and impulse control problems will predict early experimentation with drugs and alcohol.

4. Early adolescent experimentation will predict use of a greater number of drugs and more frequent use of drugs.

5. Adolescent experimentation will be related to dampening of social status as indicated by early marriage and lower socioeconomic status.

\section{METHOD}

\section{Participants}

Ninety-nine women in alcoholism treatment (19-29 years old) were interviewed for this study after detoxification. (See Gomberg, 1986, for further information regarding this study.) Participants were recruited from 21 different inpatient, outpatient, and residential treatment facilities in southeastern Michigan; there was a $7 \%$ refusal rate. Mean age at onset of problem drinking was 19.6 years. Average duration of problem drinking was 5.4 years. All women were Caucasian. Education ranged from completing eighth grade to college degrees, with $79 \%$ having a high school diploma or equivalency, and $14 \%$ having a college 
degree. Income ranged from less than $\$ 2,000$ to over $\$ 35,000$ a year. The average personal income was between $\$ 6,000$ and $\$ 8,999$. The majority of women were single (59\%): $21 \%$ were divorced, $6 \%$ were separated, and $14 \%$ were married.

\section{Measures}

The interview protocol for this study included questions relating to childhood and adolescent emotional and impulse control problems, family history of alcoholism and subsequent family disruptions, early experimentation with alcohol and other drugs, and demographic questions.

\section{Family History}

Women were asked if their mother (or mother surrogate) or father (or father surrogate) was a frequent, heavy, or problem drinker. Women who indicated that either parental figure was a problem drinker were coded as having a positive family history. Women who indicated that neither parental figure was a problem drinker were coded as having a negative family history.

\section{Family Disruption}

Women who indicated that either of their parents had an alcohol problem were asked to rate how true several statements were regarding family disruption that may have occurred as a result of their parents' drinking. Response choices were very true (3), somewhat true (2), or not at all true (1). Each of the following 6 items was answered twice, once for mother's drinking and once for father's drinking: lack of attention from mother/father, mother/father not available, family chaos (because of mother or father), no family life (because of mother or father), family fights (because of mother or father), and money problems (because of mother or father). The 12 items were summed to create the family disruptions scale $(\alpha=.91)$. Only women with a positive family history of alcoholism were asked questions regarding disruption; therefore, family disruption data are available for 48 women.

\section{Childhood Anxiety and Impulse Control}

Participants were asked to indicate whether they exhibited the following behaviors before age 12: nail biting, nightmares, bed wetting, temper tantrums, thumb sucking, phobias, tooth grinding, and "nervous problems." Items were examined individually because they were not highly correlated and could not be combined to create an internally consistent scale.

\section{Adolescent Impulse Control}

Women were asked about impulse control problems they may have exhibited during adolescence. Responses to five yes or no items were used to create an adolescent impulse control scale by counting the number of yes responses $(\alpha=.62)$. Behaviors were: ran away from home before age 18 , expelled or suspended from school, skipped school, trouble with school authorities, and dropped out of school. 


\section{Adolescent Emotional Problems}

Women were asked six questions about how often they experienced several emotions from ages 12 to 16 . Response choices were: most of the time, some of the time, hardly ever, or never. Emotions were: lonely, popular with boys, popular with girls, embarrassed with peers, bored, and nervous problems. Two items (popular with girls and boys) were reverse coded, and then the six items were summed to create a scale $(\alpha=.69)$.

\section{Adolescent Experimentation}

Women were asked if they drank or used marijuana, pills, hash, or other drugs when they were 13 to 15 years old. A three-level experimentation variable was created based on use during ages 13 to 15: (1) those who did not use alcohol or drugs, (2) those who used alcohol only, and (3) those who used alcohol and other drugs.

\section{Lifetime Drug Use}

Women were asked if they had tried each of the following drugs and how often they had used them: valium, codeine, stimulants, sleeping pills, darvon, librium, cocaine, marijuana, psychedelics, and heroin. The number of drugs ever tried was computed by counting the number of drugs tried. For frequency of use, response choices were: (a) never, (b) once or twice or occasionally, or (c) often or every day.

\section{RESULTS}

All data were double entered in a MIDAS file and later transferred to SPSSX for data analyses.

\section{Hypothesis 1}

Chi-square analyses were used to test the hypothesis that women with a positive family history of alcoholism would show childhood anxiety and impulse control problems (Table 1). $T$ tests were used to compare childhood anxiety and

Table 1. Relationship Between Childhood Anxiety and Impulse Control Problems and Family History of Alcoholism

\begin{tabular}{|c|c|c|c|}
\hline \multirow[b]{2}{*}{ Childhood Behavior } & \multicolumn{2}{|c|}{ \% Showing Childhood Behavior } & \multirow[b]{2}{*}{$x^{2}$} \\
\hline & Positive Family History & Negative Family History & \\
\hline Nail biting & 53.5 & 59.2 & 0.26 \\
\hline Nightmares & 64.8 & 55.5 & 0.71 \\
\hline Enuresis & 32.2 & 37.0 & 0.18 \\
\hline Temper tantrums & 63.3 & 63.0 & 0.001 \\
\hline Thumb sucking & 28.2 & 37.0 & 0.72 \\
\hline Phobias & 43.7 & 29.6 & 1.61 \\
\hline Teeth grinding & 31.0 & 25.9 & 0.24 \\
\hline Nervous problems & 38.0 & 29.6 & 0.60 \\
\hline
\end{tabular}


Table 2. Relationship Between (a) Childhood Anxiety and Impuse Control Problems and (b) Family Disruption

\begin{tabular}{|c|c|c|c|}
\hline \multirow[b]{2}{*}{ Childhood Behaviors } & \multicolumn{2}{|c|}{ Family Disruption } & \multirow[b]{2}{*}{$t$} \\
\hline & $M$ & $S D$ & \\
\hline \multicolumn{4}{|l|}{ Nail biting } \\
\hline Yes & 13.50 & 6.79 & \multirow{2}{*}{1.20} \\
\hline No & 15.62 & 5.04 & \\
\hline \multicolumn{4}{|l|}{ Nightmares } \\
\hline Yes & 15.06 & 6.57 & \multirow{2}{*}{-1.03} \\
\hline No & 13.18 & 5.16 & \\
\hline \multicolumn{4}{|l|}{ Enuresis } \\
\hline Yes & 13.33 & 7.01 & \multirow[t]{2}{*}{0.81} \\
\hline No & 14.88 & 5.76 & \\
\hline \multicolumn{4}{|l|}{ Temper tantrums } \\
\hline Yes & 14.07 & 6.38 & \multirow[t]{2}{*}{0.49} \\
\hline No & 14.95 & 6.06 & \\
\hline \multicolumn{4}{|l|}{ Thumb sucking } \\
\hline Yes & 15.64 & 7.82 & \multirow[t]{2}{*}{-0.89} \\
\hline No & 13.91 & 5.37 & \\
\hline \multicolumn{4}{|l|}{ Phobias } \\
\hline Yes & 15.91 & 6.24 & \multirow[t]{2}{*}{-1.57} \\
\hline No & 13.89 & 5.88 & \\
\hline \multicolumn{4}{|l|}{ Teeth grinding } \\
\hline Yes & 16.13 & 7.26 & \multirow[t]{2}{*}{-1.38} \\
\hline No & 13.58 & 5.44 & \\
\hline \multicolumn{4}{|l|}{ Nervous problems } \\
\hline Yes & 16.04 & 5.75 & \multirow[t]{2}{*}{-1.65} \\
\hline No & 13.18 & 6.23 & \\
\hline
\end{tabular}

Note. Women were asked about family disruption if they reported either parent had an alcohol problem $(n=48)$.

impulse control problems and family disruption (Table 2). In both cases, childhood anxiety and impulse control problems were not significantly related to having a positive family history of alcoholism or to family disruption.

\section{Hypothesis 2}

Multiple regressions were computed to test whether childhood anxiety and impulse control problems determined adolescent impulse control problems and adolescent emotional problems. Nonstandardized and standardized betas are shown in Table 3. For Analysis 1, childhood anxiety and impulse control problems significantly predicted adolescent impulse control problems $\left(R^{2}=.176\right.$, adjusted $\left.R^{2}=.092, R=.419\right), F(9,88)=2.09, p<.05$. Upon examining the beta weights, nervous problems, thumb sucking, and nightmares were the strongest contributors. For Analysis 2, childhood anxiety and impulse control problems significantly predicted adolescent emotional problems $\left(R^{2}=.0118\right.$, 
Table 3. Multiple Regressions of Childhood Indicators on Adolescent Impulse Control Problems and Emotional Problems

\begin{tabular}{lccccc}
\hline & \multicolumn{2}{c}{$\begin{array}{c}\text { Analysis 1: Adolescent } \\
\text { Impulse Control Problems }\end{array}$} & & \multicolumn{2}{c}{$\begin{array}{c}\text { Analysis 2: Adolescent } \\
\text { Emotional Problems }\end{array}$} \\
\cline { 2 - 3 } \cline { 5 - 6 } Variables & $\boldsymbol{B}$ & $\boldsymbol{\beta}$ & & $\boldsymbol{B}$ & $\boldsymbol{\beta}$ \\
\hline Family history & 0.502 & .042 & & -0.764 & -.097 \\
Nail biting & -0.395 & -.140 & & -0.878 & -.151 \\
Nightmares & 0.503 & .175 & & 0.942 & .158 \\
Enuresis & -0.008 & -.002 & & 0.193 & .031 \\
Temper tantrums & 0.123 & .057 & & -0.014 & -.002 \\
Thumb sucking & 0.539 & .178 & & -0.072 & -.011 \\
Phobias & 0.018 & .006 & & -1.157 & -.196 \\
Teeth grinding & -0.362 & -.118 & & -0.565 & -.089 \\
Nervous problems & 0.678 & .233 & -1.463 & -.242 \\
\hline
\end{tabular}

Note. Summary statistics: For Analysis $1(n=98), R^{2}=.176$, adjusted $R^{2}=.092, R=.419$, $F(9,88)=2.09, p<.05$. For Analysis $2(n=98), R^{2}=.0118$, adjusted $R^{2}=.117, R=.446, F(9,88)=$ $2.44, p<.05 . B=$ unstandardized regression coefficient. $\beta=$ standardized regression coefficient.

adjusted $\left.R^{2}=.117, R=.446\right), F(9,88)=2.44, p<.05$. Based on beta weights, nervous problems, phobias, and nightmares contributed most to the equation.

Discriminant analysis also was used to test the hypothesis that childhood anxiety and impulse control problems would predict experimentation with alcohol and other drugs. Table 4 shows descriptive statistics for childhood behaviors by experimentation. The overall function was not significant (Wilks's $\lambda=.820$ ), $\chi^{2}$ $(18, N=98)=18.04$. Thus, childhood anxiety behaviors did not directly determine alcohol and drug experimentation.

Table 4. Means and Standard Deviations for Childhood Indicators by Early Experimentation (Ages 13-15)

\begin{tabular}{|c|c|c|c|c|c|c|}
\hline \multirow[b]{2}{*}{ Childhood Indicators } & \multicolumn{2}{|c|}{$\begin{array}{l}\text { No Alcohol } \\
\text { or Drug Use } \\
\end{array}$} & \multicolumn{2}{|c|}{$\begin{array}{c}\text { Alcohol Use } \\
\text { Only } \\
\end{array}$} & \multicolumn{2}{|c|}{$\begin{array}{c}\text { Alcohol and } \\
\text { Drug Use }\end{array}$} \\
\hline & $M$ & $S D$ & $M$ & $S D$ & $M$ & $S D$ \\
\hline Family history & 1.67 & 0.48 & 1.63 & 0.49 & 1.83 & 0.38 \\
\hline Nail biting & $0.6 \mathrm{l}$ & 0.50 & 0.54 & 0.51 & 0.51 & 0.51 \\
\hline Nightmares & 0.64 & 0.49 & 0.54 & 0.51 & 0.66 & 0.48 \\
\hline Enuresis & 0.24 & 0.43 & 0.46 & 0.51 & 0.34 & 0.48 \\
\hline Temper tantrums & 0.52 & 0.51 & 0.58 & 0.50 & 0.76 & 0.43 \\
\hline Thumb sucking & 0.30 & 0.47 & 0.38 & 0.49 & 0.27 & 0.45 \\
\hline Phobias & 0.39 & 0.49 & 0.33 & 0.48 & 0.44 & 0.50 \\
\hline Teeth grinding & 0.18 & 0.41 & 0.38 & 0.49 & 0.34 & 0.48 \\
\hline Nervous problems & 0.30 & 0.47 & 0.33 & 0.48 & 0.41 & 0.50 \\
\hline
\end{tabular}


Table 5. Means and Standard Deviations for Adolescent Impulse Control and Emotional Problems by Early Experimentation (Ages 13-15)

\begin{tabular}{|c|c|c|c|c|c|c|}
\hline \multirow[b]{2}{*}{ Adolescent Problems } & \multicolumn{2}{|c|}{$\begin{array}{l}\text { No Alcohol } \\
\text { or Drug Use }\end{array}$} & \multicolumn{2}{|c|}{$\begin{array}{l}\text { Alcohol Use } \\
\text { Only }\end{array}$} & \multicolumn{2}{|c|}{$\begin{array}{l}\text { Alcohol and } \\
\text { Drug Use }\end{array}$} \\
\hline & $M$ & $S D$ & $M$ & $S D$ & $M$ & $S D$ \\
\hline Impulse control & 1.97 & 1.11 & 2.33 & 1.17 & 3.31 & 1.45 \\
\hline Emotional problems & 12.76 & 2.61 & 12.41 & 2.76 & 11.85 & 3.18 \\
\hline
\end{tabular}

\section{Hypothesis 3}

Discriminant analysis was used to test the hypothesis that adolescent impulse control and emotional problems would predict experimentation with alcohol and other drugs because this analysis accommodates a three-level categorical dependent variable (experimentation). Table 5 shows descriptive statistics for adolescent impulse control and emotional problems by drug and alcohol experimentation. The overall discriminant function was significant (Wilks's $\lambda=.800$ ), $\chi^{2}(4, N=99)=21.28, p<.001$; for Function 1, discriminant coefficients were .961 for adolescent impulse control problems and -.279 for adolescent emotional problems. However, the equation for Function 2, if impulse control was removed, was not significant (Wilks's $\lambda=.999), \chi^{2}(1, N=99)=0.02$. For Function 2 , discriminant coefficients were .275 for adolescent impulse control problems and .960 for adolescent emotional problems. Thus, only impulse control problem behaviors distinguished experimentation groups. The analysis correctly classified $55.5 \%$ of the cases: $58.8 \%$ of nonalcohol or nondrug users, $20.8 \%$ of alcohol users, and $73.2 \%$ of drug and alcohol users.

\section{Hypothesis 4}

An analysis of variance (ANOVA) was computed between experimentation during ages 13 to 15 and the lifetime number of drugs ever tried; results were significant, $F(2,96)=6.09, p<.01$. Alcohol and other drug users (ages 13-15) tried an average of 7.07 drugs; alcohol-only users (ages 13-15) tried an average of 5.96 drugs; nonalcohol and nondrug users (ages 13-15) tried an average of 5.29 drugs (Table 6).

In addition, chi-square statistics were used to compare lifetime frequency of use (never, once or twice or occasionally, or often or every day) and drug or alcohol experimentation from ages 13 to 15 . Early experimentation was significantly related to lifetime frequency of use of cocaine, $\chi^{2}(4, N=99)=10.33, p<$ .05 , but was not significantly related to frequency of use of valium, $\chi^{2}(4, N=99)$ $=9.29$; codeine, $\chi^{2}(4, N=99)=8.93$; stimulants, $\chi^{2}(4, N=99)=5.29$; sleeping pills, $\chi^{2}(4, N=99)=2.26$; darvon, $\chi^{2}(4, N=99)=0.63$; librium, $\chi^{2}(4, N=99)$ $=0.92$; marijuana, $\chi^{2}(4, N=99)=3.77$; psychedelics, $\chi^{2}(4, N=99)=9.38$; or heroin, $\chi^{2}(4, N=99)=4.82$. 
Table 6. ANOVA Between Experimentation and Lifetime Number of Drugs Ever Tried

\begin{tabular}{lcc}
$\begin{array}{l}\text { Substance Use } \\
\text { (Ages 13-15) }\end{array}$ & $\boldsymbol{M}$ & $\boldsymbol{S D}$ \\
\hline No alcohol or drug use & 5.29 & 2.37 \\
Alcohol use only & 5.96 & 2.51 \\
Alcohol and drug use & 7.07 & 1.92 \\
\hline
\end{tabular}

Note. $F(2,96)=6.09, p<.01$.

\section{Hypothesis 5}

To determine the impact of experimentation on dampening of social status, two different analyses were used. ANOVAs were used to compare the age of first marriage and education with experimentation groups; chi-squares were used to compare personal and family income with experimentation groups. Experimentation was not significantly related to age of first marriage, $F(2,38)=1.89$, or years of education, $F(2,96)=2.31$. Personal income was significantly different for experimentation groups, $\chi^{2}(16, N=99)=28.27, p<.05$. Early alcohol and other drug users made less than alcohol-only users, who made less than nonalcohol and nondrug users. Thus, the hypothesis that adolescent experimentation would be related to dampening of social status was generally not supported except that adolescent experimentation had a tendency to predict lower income.

\section{DISCUSSION}

In support of problem behavior theories, the most potent predictor of early substance experimentation among women in alcoholism treatment was adolescent impulse control problems or acting-out behaviors. Overall, the model was supported in that childhood anxiety and impulse control problems predicted adolescent emotional problems and impulse control problems that were related to early experimentation with alcohol and other drugs. These findings suggest that there may be developmental paths leading to alcohol and other drug use that may begin long before the use occurs. In addition, the transition from junior high to high school may be a risky period for substance experimentation.

Findings did not support the portion of the model that suggested that a positive family history of alcoholism is related to children's anxiety and impulse control problems. This finding is in contrast to the literature, which shows that family history of alcoholism is related to childhood emotional problems (Chassin et al., 1993) and impulse control problems (Fitzgerald et al., 1993). However, these studies used community samples with parents who were alcoholic and parents who were nonalcoholic and children whose alcoholism was not yet assessed. In this study, young women in alcoholism treatment were included, roughly half of whom had alcoholic parents. (See Nirenberg, Liepman, Begin, Maisto, \& Liebermann, 1990, for a similar sample of alcoholic males.) These sampling differences may account for inconsistencies found. 
Similarly, family disruption was not related to childhood behavioral problems although some literature shows such a relationship (Bennett et al., 1988). The reasons for the nonsignificant results found here may be that family disruption was not adequately assessed because only women with positive family histories for alcoholism were asked about family disruption. In addition, the small sample size for analyses involving family disruption $(n=48)$ may have limited the power to detect small effects. Regardless, the presence of childhood behavioral problems was not explained by any variables included in this study.

Early childhood anxiety and impulse control problems were related to adolescent impulse control and emotional problems. It is not surprising that women who report behavior problems in childhood also report them in adolescence. This finding, that childhood anxiety and impulse control problems continue into adolescence, may provide evidence for a problem behavior syndrome that is not developmentally stage limited.

Adolescent emotional problems were not related to early experimentation with drugs and alcohol. It may be that emotional difficulties are part of adolescence for many and do not predispose women to use substances. Adolescent impulse control problems or acting-out behaviors predicted experimentation with substances in early adolescence, which offers some support for the presence of a general problem behavior syndrome. Upon further examination, impulsive behaviors were best at distinguishing women who were not early experimenters and those who experimented with both alcohol and drugs, as opposed to those using only alcohol. One reason for the latter may be that this group consists of women who are in transition between beginning to drink alcohol and drinking alcohol in a problematic manner. Because problem drinking usually precedes the onset of other illicit drug use (Donovan \& Jessor, 1983), these problemdrinking women may soon begin to use other substances.

It is interesting that the relationship between impulse control or acting-out behaviors and alcohol and drug use is found across socioeconomic status (Harford \& Parker, 1994), family histories of alcoholism (Harford \& Parker, 1994), and genders (Robins \& Przybeck, 1985). The relationship between impulsive behaviors and experimentation may result from peer and family influences (Jessor \& Jessor, 1977; Kandel, 1978) in addition to intraindividual influences such as cognitions, personality, and biogenetics (Zucker, 1978). Future research should aim to identify further the cause of these problem behaviors. In the mean time, substance use prevention programs could target children that exhibit anxiety and impulse control problems, and adolescents showing acting-out behaviors, as high-risk groups for early experimentation with substances.

Results for the long-term effects of early experimentation on continued substance use and on dampening of social status are mixed. Although early experimenters used a greater number of drugs (seven as compared to five), they only used cocaine more frequently. Considering the young age of the women (ages 19-29), if these trends were to continue with age, they would lend support to suppositions regarding the harmful effects of early experimentation. Furthermore, because the sample consisted entirely of women in alcoholism treatment, it remains to be determined whether early users of drugs and alcohol are more 
likely to become alcoholic and/or drug addicted. Limited evidence was found for the dampening of social status based on early substance use. Whereas experimentation was related to having a lower income, it was not related to having less education or marrying younger. Future research should examine in greater detail the psychosocial impacts of early substance use including the development of problem drinking.

As with any retrospective study, interpretations of study results are limited by the design used. It is always possible that memories of childhood and adolescent events are biased by current situations or perspectives. However, these findings among women are consistent with those found for men, and nonalcoholic women using both prospective and retrospective designs (Donovan \& Jessor, 1983, 1985; Harford \& Parker, 1994; Kandel, 1989; Kumpfer \& Turner, 1991; Osgood et al., 1988; Robins \& Przybeck, 1985; Scaturo \& LeSure, 1985). Nonetheless, the design used in this study is not equipped to test causality, which is implied in the current hypotheses. Finally, the results are limited to young Caucasian women who are in treatment for alcoholism.

Further identification of the developmental paths leading to alcohol and other drug use is needed in order to design effective intervention strategies (Kandel, 1989). Finally, the idea that substance use is embedded in a more general problem behavior syndrome suggests that substance abuse prevention programs may want to broaden their approaches to focus on general acting-out behaviors. For example, programs could prevent acting out (including substance use) by promoting greater involvement in school activities (Donovan \& Jessor, 1985; Hawkins \& Weiss, 1985) or by appropriate screening and referral to counseling of high-risk children and adolescents.

\section{REFERENCES}

Bennett, L.A., Wolin, S.J., \& Reiss, D. (1988). Deliberate family process: A strategy of protecting children of alcoholics. British Journal of Addiction, 83, 821-829.

Berkowitz, A., \& Perkins, H.W. (1988). Personality characteristics of children of alcoholics. Journal of Consulting and Clinical Psychology, 56, 206-209.

Breslau, N. (1993). Daily cigarette consumption in early adulthood: Age of smoking initiation and duration of smoking. Drug and Alcohol Dependence, 33, 287-291.

Breslau, N., Fenn, N., \& Peterson, E.L. (1993). Early smoking initiation and nicotine dependence in a cohort of young adults. Drug and Alcohol Dependence, 33, 129-137.

Chassin, L., Pillow, D.R., Curran, P.J., Molina, B.S.G., \& Barrera, M., Jr. (1993). Relation of parental alcoholism to early adolescent substance use: A test of three mediating mechanisms. Journal of Abnormal Psychology, 102, 3-19.

Donovan, J.E., \& Jessor, R. (1983). Problem drinking and the dimension of involvement with drugs: A Guttman scalogram analysis of adolescent drug use. American Journal of Public Health, 73, 543-552.

Donovan, J.E., \& Jessor, R. (1985). Structure of problem behavior in adolescence and young adulthood. Journal of Consulting and Clinical Psychology, 53, 890-904.

Drake, R.E., \& Vaillant, G.E. (1988). Predicting alcoholism and personality disorder in a 33-year longitudinal study of children of alcoholics. British Journal of Addiction, 83, 799-807.

Fitzgerald, H.E., Sullivan, L.A., Ham, H.P., Zucker, R.A., Bruckel, S., \& Schneider, A.M. (1993). Predictors of behavior problems in three-year-old sons of alcoholics: Early evidence for the onset of risk. Child Development, 64, 110-123. 
Gomberg, E.S.L. (1986). Women and alcoholism: Psychosocial issues. In Women and alcohol: Heallhrelated usues (NIAAA Research Monograph No. 16; DHHS Publication No. ADM 86-1 139; pp. 78-120). Washington, DC: U.S. Government Printing Office.

Gomberg, E.S.L. (1989). Alcoholic women in treatment: Early histories and early problem behaviors. Adrance's in Alcohol and Substance Abuse, 8, 133-147.

Gomberg, E.S.L. (1991). Women and alcohol: Psychosocial aspects. In D.J. Pittman \& H.R. White (Eds.), Society, culture, and drinking pattemu rexammed. New Brunswick, NJ: Rutgers Center of Alcohol Studies.

Gomberg, E.S.L., \& Lisansky. J.M. (1984). Antecedents of alcohol problems in women. In S.C. Wilsnack \& L.J. Beckman (Eds.), Alcohol problems m women. New York: Guilford Press.

Harford, T.C., \& Parker, D.A. (1994). Antisocial behavior, family history, and alcohol dependence symptoms. Alcoholsm: Clinical and Expenmental Research, 18, 265-268.

Hawkins, J.D., \& Weiss, J.G. (1985, Winter). The social development model: An integrated approach to delinquency prevention. Joumal of Primary Prevention, 6, 73-97.

Honzik, M.P. (1984). Life-span development. Annual Revtew of Psychology, 35, 309-331.

Jessor, R., \& Jessor, S.L. (1977). Problem behavnor and psychosoctal development. A longitudinal study of youlh. New York: Academic.

Jones, M.C. (1971). Personality antecedents and correlates of drinking patterns in women. Journal of Consulting and Clinical Psychology, 36, 61-69.

Kandel, D.B. (1978). Homophily, selection, and socialization in adolescent friendships. Amertan Journal of Sociology, 84, 427-436.

Kandel, D.B. (1989). Issues of sequencing of adolescent drug use and other problem behaviors. Drugs and Soczety, 3, 55-76.

Kandel, D.B., Yamaguchi, K., \& Chen, K. (1992). Stages of progression in drug involvement from adolescence to adulthood: Further evidence for the gateway theory. Journal of Studies on Alcohol, 53, 447-457.

Kumpfer, K.L., \& Turner, C.W. (1991). The social ecology model of adolescent substance abuse: Implications for prevention. The Internalional Journal of the Addactions, 25, 435-463.

Nirenberg, T.D., Liepman, M.R., Begin, A.M., Maisto, S.A., \& Liebermann, M.P. (1990). Family history of alcoholism in males: Absence of distinguishing features for treatment matching. International Journal of the Addictions, 25, $1187-1201$.

Osgood, D.W., Johnston, L.D., O'Malley, P.M., \& Bachman, J.G. (1988). The generality of deviance in late adolescence and early adulthood. American Sociological Revew, 53, 81-93.

Robins, L.N., \& Murphy, G.E. (1967). Drug use in a normal population of young Negro men. American Journal of Public Health, 57, 1580-1596.

Robins, L.N., \& Przybeck, T.R. (1985). Age of onset of drug use as a factor in drug and other disorders. In C.L. Jones \& R.L. Batijes (Eds.), Etıology of drug abuse: Implication for prevention (NIDA Research Monograph No. 56; DHHS Publication No. ADM 85-1335). Washington, DC: U.S. Government Printing Office.

Scaturo, D.J., \& LeSure, K.B. (1985). Symptomatic correlates of alcohol abuse as a presenting problem. Joumal of Clinical Psychology, 41, 118-123.

Schulenberg, J., Dielman, T.E., \& Butchart, A.T. (1994, June). Parental and peer influences on alcohol misuse during early adolescence: Longitudinal causal models. Paper presented at the annual meeting of the Research Society on Alcoholism, Maui, HI.

Sher, K.J., Walitzer, K.S., Wood, P.K., \& Brent, E.E. (1991). Characteristics of children of alcoholics: Putative risk factors, substance use and abuse, and psychopathology. Journal of Abnormal Psychology, 100, 427-448.

Werner, E.E. (1986). Resilient offspring of alcoholics: A longitudinal study from birth to age 18. Journal of Studies on Alcohol, 47, 34-40.

Yamaguchi, K., \& Kandel, D.B. (1984a). Patterns of drug use from adolescence to young adulthood: II. Sequences of progression. American Joumal of Publuc Health, 74, 668-672.

Yamaguchi, K., \& Kandel, D.B. (1984b). Patterns of drug use from adolescence to young adulthood: III. Predictors of progression. Amencan Journal of Public Health, 74, 673-681.

Zucker, R.A. (1978). Developmental aspects of drinking through the young adult years. In H.T. Blane \& M.E. Chafetz (Eds.), Youth, alcohol and social policy. New York: Plenum. 